\title{
Plant-plant spatial association networks in gypsophilous communities: the influence of aridity and grazing and the role of gypsophytes in its structure
}

\author{
H. Saiz, C. L. Alados, and Y. Pueyo \\ Instituto Pirenaico de Ecología (IPE) - CSIC Campus de Aula Dei, Avda. Montañana, 1005, \\ 50059 Zaragoza, Spain
}

Correspondence to: H. Saiz (saizhugo@gmail.com)

Received: 29 April 2014 - Accepted: 23 June 2014 - Published: 1 August 2014

\begin{abstract}
In stressful environments many plant species are only able to survive if they benefit from the facilitative effect of "nurse" species. Typically, these nurses are species adapted to the stressful environmental conditions that favor the formation of vegetation patches, where other, less-adapted species can be established. However, ecological interactions can be influenced by abiotic and biotic factors. In this study we quantified the effect of grazing and aridity on the patch structure of gypsophilous plant communities and the role that gypsophytes, species adapted to gypsum soils, play in structuring these communities. Specifically, we created signed networks (networks with positive and negative links) at grazed and ungrazed sites in two areas in the middle Ebro Valley, Spain, that differed in aridity. We built networks connecting plant species with positive and negative links derived from the spatial associations between species. Then, we divided networks in partitions which represented the different vegetation patches present in the community. We found that vegetation patches were more specific (same species always were associated in the same patch type) in high aridity and grazed sites, where environmental conditions were the most stressful and many species persisted by associating with nurse species. Gypsophytes were more important aggregating species than nongypsophytes in grazed high aridity sites. Independently of study sites, gypsophyte shrubs acted as nurses, but small gypsophytes segregated from other species and formed monospecific patches. In conclusion, grazing and aridity influenced the patch structure of gypsophilous plant communities. Gypsophytes played an important role structuring the patch community, but this importance depended on environmental conditions and the identity of gypsophyte.
\end{abstract}

\section{Introduction}

In arid and semiarid regions, soils that have high gypsum content are widespread (Mota et al., 2011; Parsons, 1976). Gypsum soils impose severe limitations for the survival of plants, as their physicochemical features prevent seedling germination or the uptake of water and nutrients. In these soils physical and biological crusts develop on the top soil layer and form a physical barrier to plant species establishment (Awadhwal and Thierstein, 1985); and some nutrients such as $\mathrm{P}, \mathrm{K}, \mathrm{Mg}$, and $\mathrm{N}$ are scarce while others such as $\mathrm{Ca}^{+2}$ appear in toxic concentrations (Breckle, 1998; Mota et al., 2011). These particular conditions have contributed to the evolution of specialized flora in these environments: gypsophytes (Parsons, 1976). Gypsophytes have characteristics that allow them to resist the stressful conditions of gypsum soils, including the production of mucilaginous seeds, which can anchor and become established on crusted soils and maintain humidity during germination (Escudero et al., 1999), or the accumulation of soil toxic ions in their structures (Palacio et al., 2007). The specialized nature of gypsophytes contributes to their rarity and has led the European Union to treat gypsophilous communities as priority habitats (CCE, 1992).

Although gypsophilous communities have been the subject of considerable study, more remains to be known, as the nature of the interactions that gypsophytes establish with other plant species in the community. In arid regions the 
creation of microhabitats by adapted plants in which the stressful environmental conditions are ameliorated allows the persistence of nonadapted species (an interaction called facilitation, Bruno et al., 2003). Typically, those microhabitats are vegetation patches created by perennial plants that act as "nurses" and several plants that establish under their canopies (Fowler, 1986; Pugnaire et al., 1996). An understanding of the nature of the interactions between plant species is very important for the conservation of natural communities, because facilitation can be an effective tool to restore and conserve natural habitats (Castro et al., 2004; Pueyo et al., 2009). Gypsophytes are good candidates for acting as nurses and facilitating the establishment of other, lessadapted species because they are adapted to the stressful conditions of gypsum soils.

In plant communities, biotic interactions can be modulated by abiotic and biotic factors. It has been suggested that facilitative interactions become more important with increasing aridity, because nurses buffer harsh environmental conditions (Pugnaire and Luque, 2001; Pugnaire et al., 2004); and with increasing grazing intensity as palatable species benefit from spatially associating to nonpalatable species (Graff et al., 2007; but see Smit et al., 2009; Soliveres et al., 2012 for examples about the interaction between aridity and grazing). However, in gypsum soils moderate grazing intensities can result in a decrease of importance of facilitative interactions as the trampling of herbivores can break the soil crust and increase water infiltration, which enhances seeds establishment and survival (du Toit et al., 2009; Pueyo et al., 2013). Thus, how grazing modulates biotic interactions in a gypsum environment is unknown. We may expect that facilitation plays a predominant role in most stressful and ungrazed environments where gypsophytes are more common (Pueyo et al., 2008).

Typically, studies of plant-plant interactions have focused on specific pairs of species and the direct effect that a particular species (nurse) has on another (Pugnaire et al., 1996; Howard and Goldberg, 2001). However, this approach includes only a small portion of all the interactions that occur in an ecosystem and recently facilitation has started to be studied at community level (Cavieres et al., 2006; ValienteBanuet and Verdu, 2007; Soliveres et al., 2012). From the second half of the 20th century, the network approach has been a common tool to study interactions at the community level by ecologists (Bascompte, 2007; Heleno et al., 2014). Treating species as nodes within a network allows the identification of properties of the communities and the roles that species play within the community, which cannot be addressed otherwise (Ings et al., 2009). However, the use of ecological networks has focused on a few types of systems (predator-prey, pollination and seed dispersal mutualisms, and parasitism; Ings et al., 2009), while neglecting others. This is particularly evident for plant communities, even though facilitation and competition among plant species are major structural forces in these communities (but see Verdu and Valiente-Banuet, 2008, 2011, to see an example of network analysis in plant communities).

In this study we used a network approach to quantify the structure of the interspecific interactions in gypsophilous plant communities and the role that gypsophytes play in structuring these communities. To our knowledge, this is the first study to assess plant-plant interactions in a gypsophilous community at community level. We built plantplant signed networks (sensu lato, networks with positive and negative links) considering the spatial association between species in the community. Spatial patterns among plant species are a suitable indicator of the nature of the interactions among plants (Tirado and Pugnaire, 2005; Cavieres et al., 2014). Specifically, we identified vegetation patches of gypsophilous plant communities in areas that differed in aridity and livestock grazing intensity. Vegetation patches were built attending to the structural balance criterion for signed networks, grouping in the same partition nodes which share positive links while separating nodes negatively linked (Doreian and Mrvar, 2009). We considered that each partition (sensu lato, group of species spatially associated among them and segregated from other species) represented a particular type of vegetation patch in the community. We analyzed the specificity of the vegetation patches in the community (i.e., the same species always were associated in the same patch type) and the role of gypsophytes forming and differentiating those patches. We hypothesized that gypsophytes act as nurses forming vegetation patches where other plant species establish. We propose that (a) in high aridity ungrazed site gypsophilous plant community presents most specific vegetation patches and positive interactions are the most important because environmental conditions are the most stressful; and (b) gypsophytes have a significant role in structuring vegetation patches at the highly arid and ungrazed sites as they are the best-adapted species to that environment.

\section{Methods}

\subsection{Study area}

The study was conducted at the la Lomaza wildlife refuge (municipality of Belchite) and the Alcubierre Mountain range (municipality of Leciñena) in the middle Ebro Valley, Zaragoza, Spain. Both areas have gypsum soils that have high gypsum content, but La Lomaza is more arid than Alcubierre (Table 1). Several gypsophytes occur at both locations such as Helianthemum squamatum (L.) Pers., G. struthium subsp. hispanica and Ononis tridentata L., but some other species are only present at one of these locations. Among the nongypsophytes, small shrub species such as Thymus vulgaris L. and grasses such as Lygeum spartum (L.) Kunth. are common in La Lomaza, and tall shrub species such as Rosmarinus officinalis L. and Cistus clusii Dunal predominate in Alcubierre (Braun-Blanquet and Bolos, 1957). At each location a grazed and an ungrazed site were selected for 
the study. Personal interviews with landowners confirmed the grazing management practices and were used to calculate the stocking rate (Table 1). Stocking rates corresponded to traditional grazing management practices in the region and moderate grazing intensities (Robles and Passera, 1995). Thus, the study included four sites: one ungrazed (HU) and one grazed (HG) site at the most arid location, La Lomaza, and one ungrazed (LU) and one grazed (LG) site at the least arid location, Alcubierre (Table 1).

\subsection{Vegetation survey and data analysis}

At the four study sites vegetation was surveyed using the point-intercept method (Goodall, 1952). The point-intercept method has limitations to account for rare species (Van de Maarel and Franklin, 2005); thus, we recorded a large number of points at each site to overcome this problem. At each site, six $250 \mathrm{~m}$ long linear transects were established and the plants that were in contact with the transect line in points at $20 \mathrm{~cm}$ intervals were recorded in May and June 2010 ( $T=1251$ points per transect, $1251 \times 6=7506$ points per site). The presence of all the species was registered, regardless of its life stage. We identified four gypsophytes: Hel. squamatum, Herniaria fruticosa L., G. struthium subsp. hispanica and $O$. tridentata (Mota et al., 2011), all of which were present at the four sites. For each transect, we calculated the abundance of each species $i\left(n_{i}\right)$, total species richness $(S)$, community evenness $\left(E=H^{\prime} / \ln (S)\right.$, where $H^{\prime}$ is Shannon diversity index, $H^{\prime}=\sum_{i=1}^{S} p_{i} \ln p_{i}$, where $p_{i}$ is the proportion of $n_{i}$ respect the total plant abundance in each transect), abundance of gypsophytes (Gypso, sum of the abundances of all gypsophytes in the transect) and the amount of bare soil (BS, number of points in the transect where no species were present $/ T$ ). Differences between sites were evaluated using generalized linear models that included aridity (low or high) and grazing (ungrazed or grazed) as fixed factors, in R software (http://www.Rproject.org).

\subsection{Network construction and analysis}

To quantify plant community organization at each site, six plant-plant spatial association networks (one network per transect) were created based on the transect data. In these networks, the nodes $(i, j)$ are plant species and the links $\left(l_{i j}\right)$ represent the spatial association between each pair of species in the transect. The spatial association between each pair of species was calculated comparing the number of cooccurrences of the two species on the transect and the number of expected co-occurrences based on their abundances. The number of co-occurrences of a pair of species $i$ and $j\left(a_{i j}\right)$ was the number of points in the transect where $i$ and $j$ appeared together, and the expected number of cooccurrences for each pair of species $i$ and $j\left(e_{i j}\right)$ was $e_{i j}=$ $n / T \times n / T \times T$ (i.e., the probability of finding $i$ and $j$ at the same point on the transect multiplied by the total number of points in the transect; Saiz and Alados, 2012).

To compare the $e_{i j}$ and $a_{i j}$ for each pair of species, we calculated the lower $\left(e_{i j}^{-}\right)$and upper $\left(e_{i j}^{+}\right)$limit of the $95 \%$ confidence interval of the Poisson distribution fitted with $e_{i j}$. The spatial association between species $i$ and $j$ was defined as follows:

$l_{i j}=1$ if $a_{i j}>e_{i j}^{+}$,
$l_{i j}=-1$ if $a_{i j}<e_{i j}^{-}$,
$l_{i j}=0$ if $a_{i j} \geq e_{i j}^{-}$and $a_{i j} \leq e_{i j}^{+}$.

The spatial association between $i$ and $j$ is positive if $a_{i j}>e_{i j}^{+}$, and negative if $a_{i j}<e_{i j}^{-}$.

We calculated the following indices from the network: the proportion of nonassociative species (NAs $=1-S^{\prime} / S$, where $S^{\prime}$ is the number of species that have at least one significant spatial association), and the number of links per species ( $D=L / S$, where $L=\sum_{i=1}^{\mathrm{S}} \sum_{j=1}^{\mathrm{S}}\left|l_{i j}\right|$ ). The proportion of nonassociative species and the number of links per species reflect the random spatial association between plant species in the community. High NAs indicates that several species do not present any significant spatial association in the community, and low $D$ indicates that the spatial association between most species is neutral. The balance between positive and negative associations was measured using the association ratio $\left(\right.$ ratio $=\left(L^{+}-L^{-}\right) /\left(L^{+}+L^{-}\right)$, where $L^{+}$is the number of positive links and $L^{-}$is the number of negative links in the network). The association ratio reflects the predominant type of links in the network (a positive ratio value indicates that positive links are more common than negative links, while a negative ratio value indicates the converse). Differences between sites in their network characteristics were tested in $\mathrm{R}$ using generalized linear models, which included aridity and grazing as fixed factors.

\subsection{Network partitioning and importance of gypsophytes}

Each network was divided in $M$ partitions based on the structural balance criterion (Traag and Bruggeman, 2009). A network that has positive and negative links is balanced if all of its nodes can be assigned to one unique partition, such that all of the links between nodes that conform a partition are positive $\left(l_{i j}=+1\right.$ for every $i$ and $j$ within a partition) and all of the links between nodes that conform different partitions are negative $\left(l_{i j}=-1\right.$ for every $i$ and $j$ in different partitions; Doreian and Mrvar, 2009). In our study, the partitions represented the different types of vegetation patches that occurred in the ecosystem, and distinguished between patches based upon the specific species present in each type of patch (Fig. 1). If there were isolated blocks of species (i.e., the network could be divided in subnetworks that were not connected), each subnetwork was assigned to its own partition (i.e., they were considered different vegetation patches). 
Table 1. Characteristics of the study sites in the middle Ebro Valley, Spain.

\begin{tabular}{lllrrr}
\hline Code & Site & Coordinates & $\begin{array}{r}\text { Aridity } \\
\left({ }^{\circ} \mathrm{Cmm}^{-1}\right)\end{array}$ & $\begin{array}{r}\text { Grazing (in } \\
\text { ha }^{-1} \text { year }\end{array}$
\end{tabular}

Based on the structural balance criterion, networks might be unbalanced systems because they can have links that do not meet balance criteria (i.e., not all of the links within a partition are positive or not all of the links between partitions are negative; Doreian and Mrvar, 2009). An index of frustration can quantify the extent to which a network deviates from perfectly balanced organization. As an index of frustration, we used the proportion of all of the links in the network that did not meet the structural balance criterion $\left(F=\left(\left(l_{M_{\mathrm{x}}} \neq+1\right)+\left(l_{M_{\mathrm{x}}, M_{\mathrm{y}}} \neq-1\right)\right) / L\right.$, where $l_{M_{\mathrm{x}}}$ is the number of links within the partition $M_{\mathrm{x}}$, and $l_{M_{\mathrm{x}}, M_{\mathrm{y}}}$ is the number of links between partitions $M_{\mathrm{x}}$ and $M_{\mathrm{y}}$ ). Here, $F$ reflects the specificity of the vegetation patches in the community (i.e., the same species were always associated to the same patch type): communities that have low $F$ values have high species-specific patches. Network partitioning was performed using Pajek (http://pajek.imfm.si/doku.php).

In a partitioned network, the role that each node has in the organization of the network can be assessed, based on its intrapartition degree and participation (Guimera and Amaral, 2005). Intrapartition degree $\left(I_{i}\right)$ measures the extent to which a node is connected to the other nodes within its partition. Specifically,

$I_{i}=\left(l_{i, M_{\mathrm{x}}}-D_{M_{\mathrm{x}}}\right) / \sigma_{D_{M_{\mathrm{X}}}}$,

where $l_{i, M_{\mathrm{x}}}$ is the number of links of $i$ within the partition $M_{\mathrm{x}}, D_{M_{\mathrm{x}}}$ is the number of links per node within $M_{\mathrm{x}}$, and $\sigma_{D_{M_{\mathrm{X}}}}$ is the standard deviation of the number of links per node within $M_{\mathrm{x}}$. A positive $I_{i}$ indicates that $i$ is more connected than the average within the partition, and a negative $I_{i}$ indicates that $i$ is less connected than the average. Here, $I_{i}$ reflected the extent to which a species aggregated other species in the vegetation patches where it occurred.

Participation $\left(P_{i}\right)$ measures the extent to which a node is connected to all of the partitions in a network. Specifically,

$P_{i}=1-\sum_{x=1}^{M}\left(l_{i, M_{\mathrm{x}}} / l_{i}\right)^{2}$

where $l_{i}$ is $i$ total number of links. A $P_{i}$ close to 1 indicates that $l_{i}, M_{\mathrm{x}}$ is similar for all of the $M$ partitions in the network $\left(l_{i}, M 1 \approx l_{i}, M 2 \ldots\right)$, and a $P_{i}$ close to 0 indicates that most of the links of $i$ are concentrated within a specific partition. In our study, $P_{i}$ indicated the importance of a plant species in differentiating among vegetation patches in the plant community.

The $I_{i}$ and $P_{i}$ of gypsophytes represented their importance in the network. In each network, species were assigned to a group: species that had a low or a high intrapartition degree, and species that had a low or a high participation. Important species were more likely to be in the high $I_{i}$ and in the high $P_{i}$ groups. We assessed the importance of a species in two ways: the importance of a species in attracting other species in the vegetation patches (which was reflected by Ih, the proportion of times that species occurred in the high $I_{i}$ group), and the importance of a species in differentiating vegetation patches (which was reflected by $\mathrm{Ph}$, the proportion of times that species occurred in the high $P_{i}$ group). Groups were built using Ward's clustering method and including all of the species present in the network (Ward, 1963). For each study site, the importance of gypsophytes in the network was assessed using contingency tables that included low and high $I_{i}$, or low and high $P_{i}$ values and plant type (gypsophyte or nongypsophyte) as categories. In addition, the effects of aridity and grazing on the importance of gypsophytes were assessed using chi-square tests, with study site as category. Contingency tables were built including the data from all transects at each site. The importance of each species of gypsophyte was assessed by comparing the Ih and Ph for all gypsophytes with a chi-square test, including the data from all transects. Group clustering and proportion comparisons were performed with $\mathrm{R}$.

\section{Results}

\subsection{Effects of aridity and grazing in plant communities and network structures}

At the study sites in the middle Ebro Valley, Spain, the interaction between aridity and grazing had a significant effect on species richness $(S, p<0.001)$, evenness $(E, p=0.0149)$ and the abundance of gypsophytes (Gypso, $p<0.001)$. At the low aridity sites, grazing increased $S, E$ and Gypso; however, 
A
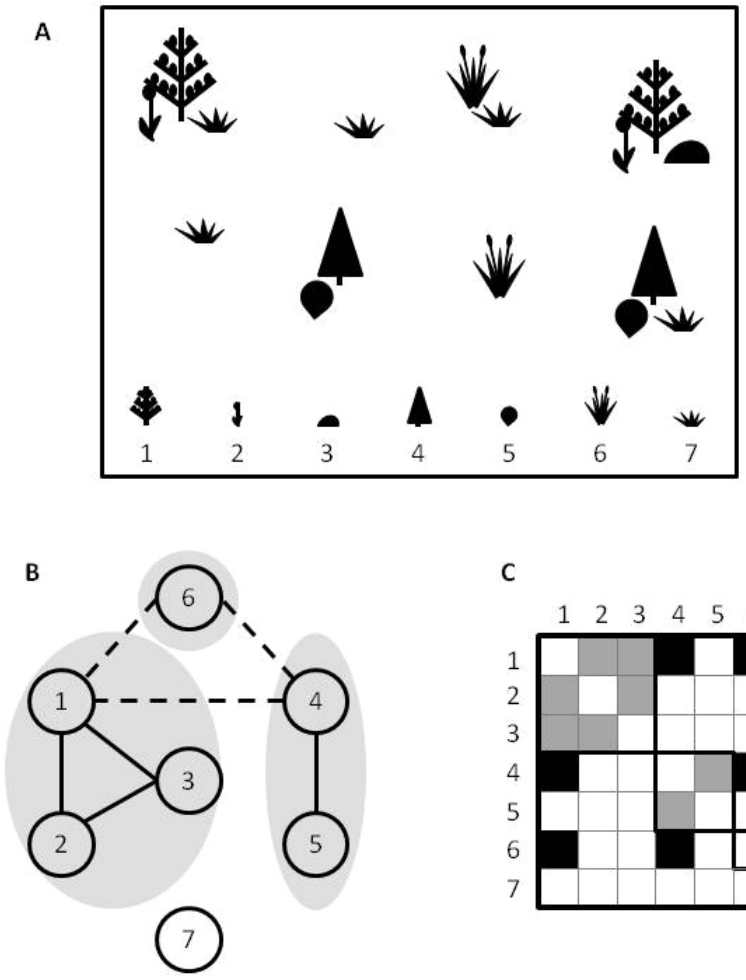

C

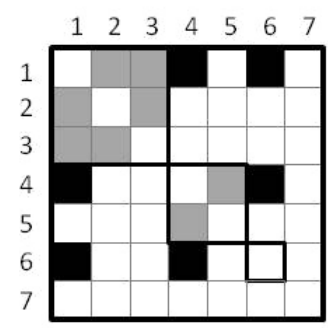

Figure 1. Ecological meaning of partitions in plant-plant spatial association networks. (A) Spatial association of plant species. Species can associate forming a multispecific vegetation patch (species 1,2 and 3 always co-occur in space), can segregate separating different types of vegetation patches (species 1,4 and 6 never co-occur in space), or can associate randomly (species 7 co-occurs with all species but also appears alone). (B) Plant-plant spatial association networks. Nodes represent species and links represent the spatial association between pairs of species (complete lines are positive spatial associations, and dashed lines are negative spatial associations). Network is divided in partitions (grey circles), so that species within a partition connect with positive links (species 1, 2 and 3) while species from different partitions connect with negative links (species 1, 4 and 6). Nodes that do not connect to others (species 7) are not included in any partition. (C) Matrix for plant-plant spatial association networks. Nodes are rows and columns of the matrix and the intersection between two nodes represents their link (grey squares are positive links, while black squares are negative links). Partitions are represented as blocks within the network, so that positive links fall within partitions, and negative links fall outside.

at the high aridity sites, grazing did not have a significant effect on $S$ and $E$, and reduced Gypso (Table 2). Thus, aridity modulated the effects of grazing in the plant communities. Aridity and grazing had a significant effect on the amount of BS ( $p<0.001$ and $p=0.0104$, respectively). BS was higher at the high aridity sites than it was at the low aridity sites, and grazing increased BS independently of aridity (Table 2).

The interaction between grazing and aridity had a significant effect on the proportion of NAs and $D(p=0.002$ and $p=0.002$, respectively). At the low aridity sites, graz-
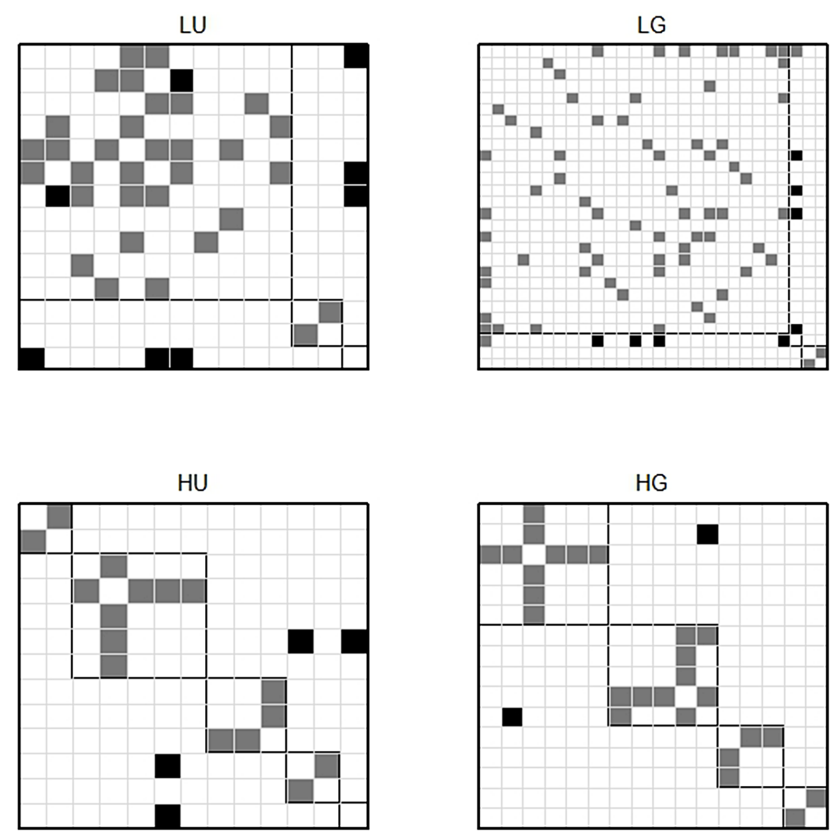

Figure 2. Plant-plant spatial association networks of the plant community at four sites in middle Ebro Valley, Spain. Study site refers to the sites with the lowest $(\mathrm{L})$ and the highest $(\mathrm{H})$ aridity index values and whether a site was grazed $(\mathrm{G})$ or ungrazed (U). Matrices were divided in partitions, which represented the different types of vegetation patches in the community. Partitions were created following a structural balance criterion. Positive associations (grey squares) fell within, and negative associations (black squares) fell outside of partitions. Matrices were based on the transect number 6 at each study site.

ing reduced the proportion of NAs and increased $D$. At the high aridity sites, grazing did not have a significant effect on NAs or $D$ (Table 3 ). Grazing increased the association ratio (ratio, $p=0.003$ ) and reduced the number of partitions in the network $(M ; p=0.041)$, independently of aridity (Table 3), which indicates that plant species aggregated in vegetation patches where grazing occurs; however there were more types of patches where grazing was absent. Networks were more balanced (i.e., $F$ was lower, $p<0.001$ ) at the high aridity sites than they were at the low aridity sites (Table 3 ), which suggests that spatial associations among plant species in vegetation patches were more species-specific in the high aridity sites because plant species preferentially associated with the same species, rather than with any given species in the community (Fig. 2). 
Table 2. Characteristics of the plant community at the four study sites in the middle Ebro Valley, Spain.

\begin{tabular}{lllll}
\hline Study site & Species richness & Evenness & Gypso & Bare soil cover \\
\hline LU & $26.5 \pm 1.48$ & $0.65 \pm 0.02$ & $63 \pm 8.39$ & $0.42 \pm 0.02$ \\
LG & $42.83 \pm 2.61$ & $0.77 \pm 0.01$ & $115.67 \pm 9.17$ & $0.46 \pm 0.02$ \\
HU & $29.17 \pm 2.57$ & $0.71 \pm 0.02$ & $174.67 \pm 25.82$ & $0.59 \pm 0.02$ \\
HG & $27.83 \pm 1.22$ & $0.74 \pm 0.01$ & $77.17 \pm 9.82$ & $0.68 \pm 0.03$ \\
\hline
\end{tabular}

Study site refers to the sites with the lowest $(\mathrm{L})$ and the highest $(\mathrm{H})$ aridity index values and whether a site was grazed $(\mathrm{G})$ or ungrazed (U). Gypso, sum of the abundances of all the gypsophytes that occurred on linear transects. All values are given as mean \pm standard error.

Table 3. Characteristics of the spatial association networks of the plant community at the four study sites in the middle Ebro Valley, Spain.

\begin{tabular}{llllll}
\hline Study site & Proportion of nonassociative species & Linkage per species & Association ratio & Number of partitions & Frustration \\
\hline LU & $0.43 \pm 0.03$ & $1.3 \pm 0.13$ & $0.53 \pm 0.06$ & $4.17 \pm 0.6$ & $0.06 \pm 0.02$ \\
LG & $0.23 \pm 0.03$ & $2.26 \pm 0.15$ & $0.83 \pm 0.02$ & $2.67 \pm 0.56$ & $0.04 \pm 0.01$ \\
HU & $0.39 \pm 0.04$ & $1.24 \pm 0.21$ & $0.67 \pm 0.1$ & $4.83 \pm 0.4$ & $0.01 \pm 0.01$ \\
HG & $0.42 \pm 0.04$ & $1.08 \pm 0.12$ & $0.87 \pm 0.05$ & $3.33 \pm 0.33$ & $0.01 \pm 0.01$ \\
\hline
\end{tabular}

Study site refers to the sites with the lowest $(\mathrm{L})$ and the highest $(\mathrm{H})$ aridity index values and whether a site was grazed $(\mathrm{G})$ or ungrazed (U). Frustration was calculated as the proportion of links that did not fulfill the structural balance criterion.

\subsection{Importance of gypsophytes in structuring plant communities}

Gypsophytes appeared in the high intranode degree group $43 \%$ of the time $(\mathrm{Ih}=0.43)$, which suggests that they had an important role aggregating species in the study area, while they appeared in high participation groups $10 \%$ of the time $(\mathrm{Ph}=0.1)$. Furthermore, gypsophytes were more important, aggregating other species in vegetation patches than the nongypsophytes in the plant community only at the high aridity, grazed site (HG; Fig. 3). Neither aridity nor grazing had a significant effect on the importance of gypsophytes in the plant communities $\left(\chi^{2}=0.463, p=0.927\right)$. Thus, it appears that gypsophytes played a role in aggregating species in the plant community independently of environmental conditions, but they were not more important than nongypsophytes.

Attending to the importance of gypsophytes, there were no significant differences between the species $\left(\chi_{\mathrm{Ih}}^{2}=5.537\right.$, $p_{\text {Ih }}=0.136, \chi_{\mathrm{Ph}}^{2}=2.177, p_{\mathrm{Ph}}=0.536$, Fig. 4). Visual analysis of the proportions suggests that Gypsophila struthium subsp. hispanica and Ononis tridentata were more important aggregating species in the plant community than the other gypsophytes (Fig. 4a), but the difference was not significant. These results suggest that species-specific aggregation in vegetation patches was not strongly linked to the specialization to gypsum soils of benefactor species.

\section{Discussion}

\subsection{Effects of aridity and grazing in plant communities and network structure}

Biotic (grazing) and abiotic (aridity) factors significantly affected the structure of plant communities on gypsum soils in the middle Ebro Valley. Grazing increased the amount of bare soil and the ratio of positive-to-negative plant-plant associations in the communities. Consumption of plant biomass by herbivores reduces vegetation cover, which increases the amount of bare soil (McNaughton, 1986; Milchunas and Lauenroth, 1993), and also increases the spatial association between grazing-resistant and vulnerable species as it is a common defense mechanism against grazers of plants (Olff and Ritchie, 1998). In addition, as presented in the hypothesis, grazing reduced the number of partitions in the network (i.e., grazed communities presented less types of vegetation patches). Plant consumption and trampling by herbivores can disrupt the plant community structure in arid environments by randomizing the organization of vegetation patches, which creates a more homogeneous distribution of plant species among patches (Adler et al., 2001). This homogenization increases the similarity among vegetation patches in a plant community.

In our study, plant-plant spatial association networks indicated that positive interactions dominated over negative interactions in all study sites, but this dominance did not vary with aridity. Theory posits that positive interactions become more frequent in natural communities as stress increases (Bertness and Callaway, 1994), but more recent formulations show that this relationship is unimodal when stress is based on resource limitation (Maestre et al., 2009). In our case we did not find 


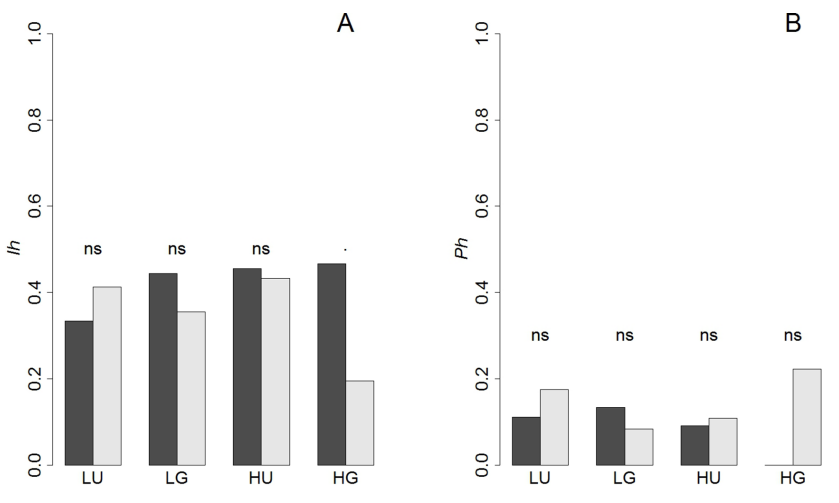

Figure 3. Importance of gypsophytes in the plant association networks at the four study sites in the middle Ebro Valley, Spain. Study site refers to the sites with the lowest $(\mathrm{L})$ and the highest $(\mathrm{H})$ aridity index values and whether a site was grazed $(\mathrm{G})$ or ungrazed (U). (A) Proportion of times that plant species appeared in a high intrapartition degree group (Ih) at each study site. (B) Proportion of times that plant species appeared in high participation group $(\mathrm{Ph})$ at each study site. Bars include the proportion of times that a gypsophyte (dark bars) or a nongypsophyte (light bars) appeared in a high value group (Ih and $\mathrm{Ph}$ ). Nonsignificant differences between gypsophytes and nongypsophytes at each site are represented by ns, while marginally significant differences $(p$ values $<0.1)$ are represented by "•".

significant effects because, as we only have two aridity levels, the difference in stress intensity might not have been sufficient to test this hypothesis (Maestre et al., 2006). However, specificity of vegetation patches was higher at high aridity sites. High aridity contributes to more restrictive soil conditions and a thick soil crust (reflected by the large amount of bare soil in HU and HG sites; Pueyo et al., 2007), which results in a plant community that is highly specialized for resisting those types of stresses (Escudero, 2009). In high aridity sites, gypsum-tolerant species created the vegetation patches of the community (e.g., with roots that can break through the soil crust; Romao and Mota, 2005), and the composition of these patches was highly species-specific. This result coincides with our initial hypothesis and other works suggesting that facilitative interactions are related to speciesspecific attributes like indirect facilitation or differential response to allelopathy (Soliveres et al., 2012). At the low aridity sites environmental conditions are more benign, which can be related to an increase of competition in the community as a result of an increase in the relative abundance of competitor species (Michalet et al., 2006). Thus, although the decrease in the importance of positive interaction was not significant, less species-specific vegetation patches suggests that facilitated species competed amongst themselves for the space under nurses, but were not associated to a specific patch type.

We also found that the effect of livestock grazing on several community indices was modulated by aridity. At the
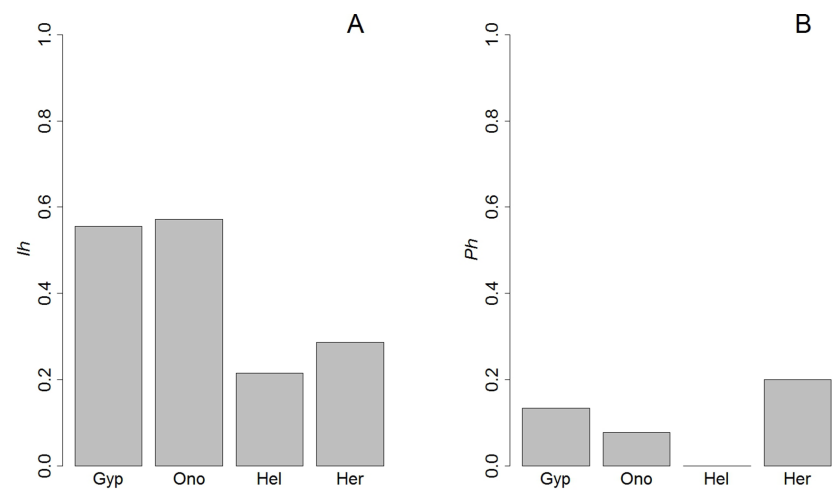

Figure 4. Importance of each gypsophyte species in the study area of the middle Ebro Valley, Spain. Gypso: G. struthium subsp. hispanica; Ono: O. tridentata; Hel: Hel. Squamatum; Her: Her. fruticosa. (A) Proportion of times that each gypsophyte appeared in high intrapartition degree group (Ih) in the study area. (B) Proportion of times that each gypsophyte appeared in high participation group $(\mathrm{Ph})$ in the study area. There were no significant differences between gypsophytes.

high aridity sites, grazing did not affect species richness and reduced the abundance of gypsophytes. Grazing increases the bare soil cover in arid environments and the number of species tends to decrease at local scales, which results in a decreasing or constant trend for richness with grazing intensity (de Bello et al., 2007). Attending to gypsophytes, grazing can affect the hydrophysical properties of the soil by removing the surface soil crust (du Toit et al., 2009), resulting in a more benign environmental condition which can limit the establishment of specialized flora. At the low aridity sites, however, livestock grazing increased species richness, community evenness and gypsophytes abundance. At the low aridity sites, the plant community was dominated by $R$. officinalis and herbivores that feed on it (although $R$. officinalis is not as nutritious as other species, it was very common and easy to find in the community; Barrantes et al., 2004). Thus, grazing created gaps on vegetation where other species (including gypsophytes) became established (Rook et al., 2004) and reduced the abundance of the dominant species (Olff and Ritchie, 1998). These species created new vegetation patches where other species became established, providing protection against grazers and resulting in an increase of the density of links in the network.

Although widely employed to study food webs or plantpollinator systems, the analysis of interactions in plant communities with networks remains scarce (Verdu and ValienteBanuet, 2008, 2011). Traditionally, plant community structure has been studied with multivariate methods or incidence matrices. Multivariate methods study the structure of the communities by grouping species which shared similar properties (e.g., cluster analysis), and linking community species to environmental properties (e.g., principal component analysis; James and McCulloch, 1990). However, these methods 
do not specifically address biotic interactions among species. Incidence matrices employ co-occurrence patterns among species to describe species assembly rules of the community, which can be related to biotic interactions, but do not focus on the specific role of species in the community (Gotelli, 2000). In contrast, network analyses are specifically meant to study the interactions established among organisms, and provide valuable information about the general structure of the community and the role that each species plays in that structure (Newman, 2003). Thus, we believe that networks are a valuable method to identify species which play a key role sustaining the structure of the plant community through their biotic interactions.

\subsection{Importance of gypsophytes structuring plant communities}

In the middle Ebro Valley, gypsophytes had a more important role than the other species in the plant communities only in one site $(\mathrm{HG})$; however, neither aridity nor grazing had a significant effect on their overall importance. Independently of the presence of gypsophytes, some nongypsophytes, particularly dominant species such as $L$. spartum and $R$. officinalis, formed vegetation patches and played a significant role in the plant communities. At high aridity sites, vegetation patches were formed by gypsophytes and L. spartum (in $\mathrm{HU}, \mathrm{Ih}_{\text {lygeum }}=0.8, \mathrm{Ph}_{\text {lygeum }}=1$ ), which is a very thick grass that can survive in gypsum soils, that can survive in gypsum soils and allows several small plant species tp establish at its edges (Pugnaire et al., 1996). At those sites, grazing reduced the abundance of L. spartum, and gypsophytes became more important in aggregating other species. At low aridity sites, vegetation patches were formed by $R$. officinalis (in LU, $\mathrm{Ih}_{\text {Rosmarinus }}=0.67, \mathrm{Ph}_{\text {Rosmarinus }}=0.83$ ), which is a shrub taller than the gypsophytes and dominates the space in the community. Rosmarinus officinalis created low-diversity patches, and displaced most of the plant species in the community to the gaps that it did not occupy. That dominance could be associated with an allelopathic strategy that is typical of several species that are in the same genus or family (Angelini et al., 2003). Grazing reduced the abundance of $R$. officinalis, which allowed gypsophytes to form vegetation patches that differed from those of $R$. officinalis (but differences were not statistically significant; Fig. 3).

There were no significant differences in the importance of gypsophytes structuring the networks. However, Fig. 4 suggests that $G$. struthium subsp. hispanica and $O$. tridentata were more important in aggregating species (Ih). These species are tall shrubs, while Hel. squamatum and Her. fruticosa are smaller. Typically, shrubs are responsible for the formation of vegetation patches in semiarid environments (Sala and Aguiar, 1995) and bigger canopy size is related to more facilitated species richness (Tewksbury and Lloyd, 2001). Furthermore, a chi-square analysis comparing the importance of tall and small gypsophytes $\left(\mathrm{Ih}_{G \text {. struthium }}+\mathrm{Ih}_{O \text {. tridentata }}\right.$ vs. $\mathrm{Ih}_{\text {Hel. squamatum }}+\mathrm{Ih}_{\text {Her. fruticosa }}$ ) showed significant differences between both groups $\left(\chi_{\text {Ihtallvs small }}^{2}=4.192\right.$, $\left.p_{\text {Ihtall vs small }}=0.041\right)$. Gypsophylla struthium subsp. hispanica formed vegetation patches in which several plant species became established, but at the low aridity sites where plant community was dominated by $R$. officinalis, G. struthium subsp. hispanica did not form proper patches. On the contrary, Ononis tridentata formed vegetation patches in the low aridity sites (it was less abundant at high aridity sites, $n_{\text {ononis }}=5 \pm 1.03$ in high aridity sites; $n_{\text {ononis }}=30.4 \pm 4.73$ in low aridity sites; values are presented as mean \pm standard error). In high aridity sites $O$. tridentata presented low coverage and, thus, did not contribute to community structure as did the other, more abundant gypsophyte shrub G. struthium subsp. hispanica.

The other gypsophytes, Hel. squamatum and Her. fruti$\cos a$, did not aggregate other species. Those species present smaller canopies and tend to occur in monospecific patches at all of the study sites. This can be explained by different mechanisms. For example, as they are small plants, it is unlikely that they can facilitate other species, (Sala and Aguiar, 1995). Furthermore, they can establish on bare soil (where others cannot) because they have traits that make them adapted to semiarid environments (e.g., the seeds of Hel. squamatum present mucilage, which helps them to anchor to the soil surface; Escudero et al., 1999). Thus, it appears that plant traits (e.g., plant size, life form) are more important in structuring vegetation patches in gypsophilous plant communities than the tolerance to gypsum soils.

\section{Conclusions}

The analysis of plant-plant spatial association networks revealed that abiotic and biotic factors such as aridity and livestock grazing influence the structure of plant communities on gypsum soils in the middle Ebro Valley, Spain. At the high aridity sites, grazing reduced the abundance of gypsophytes, but they continued conforming vegetation patches of the plant community. However, at the low aridity sites, grazing reduced the dominance of a few species, which enabled the establishment of other species that can form vegetation patches. Gypsophytes played an important role in structuring the vegetation patch organization in the plant communities on gypsum soils, independently of environmental factors. For example, tall gypsophyte shrubs such as G. struthium subsp. hispanica and $O$. tridentata were important in aggregating species, while small gypsophytes such as Hel. squamatum and Her. fruticosa did not because they were able to establish themselves on bare soils, where other species cannot. In addition to the gypsophytes, other species such as $L$. spartum or $R$. officinalis played an important role in structuring vegetation patches. To understand the mechanisms that drive the organization of gypsophilous communities, it is important to 
consider both the biotic and the abiotic environmental factors that might be operating, in addition to the role of gypsophytes. However, other less specialized species might also play a significant role in the structuring process. Communitylevel approaches such as plant-plant networks might help to find the keystone species and improve our understanding about the most important processes that underlie ecosystems.

\section{Author contributions}

H. Saiz, C. L. Alados and Y. Pueyo defined hypotheses, did vegetation surveys and discussed obtained results. H. Saiz built the networks, calculated the partitions and wrote the manuscript.

Acknowledgements. The study was made possible by the financial support of projects GA-LC-020/2010 (from the Government of Aragon), CGL2011-27259 and CGL2012-375080 (from Ministerio de Economía y Competitividad co-financed by FEDER), and grant JAEPre from the National Research Council of Spain. We are grateful to P. Nuche, Y. Kouba, B. Komac, P. Sanchez, and M. L. Dehesa for helping with the fieldwork. SEO/Birdlife and the Gobierno de Aragón kindly permitted access to the Refugio de fauna Silvestre de la Lomaza de Belchite.

Edited by: R. Heleno

Reviewed by: S. Soliveres and one anonymous referee

\section{References}

Adler, P. B., Raff, D. A., and Lauenroth, W. K.: The effect of grazing on the spatial heterogeneity of vegetation, Oecologia, 128, 465479, 2001

Angelini, L. G., Carpanese, G., Cioni, P. L., Morelli, I., Macchia, M., and Flamini, G.: Essential oils from Mediterranean lamiaceae as weed germination inhibitors, J. Agr. Food Chem., 51, 6158-6164, 2003.

Awadhwal, N. K., and Thierstein, G. E.: Soil crusts and its impact on crop establishment: a review, Soil Till. Res., 5, 289-302, 1985.

Barrantes, O., Reine, R., Ascaso, J., Mendoza, A., Broca, A., and Ferrer, C.: Pastos arbustivos y pastizales del tipo lasto-timoaliagar de la depresion del Ebro en la provincia de Huesca. Tipificacion, cartografia y valoracion, Actas de la XLIV reunion cientififica de la Sociedad Española para el Estudio de los Pastos, 601-606, 2004.

Bascompte, J.: Networks in ecology, Basic Appl. Ecol., 8, 485-490, 2007.

Bertness, M. D. and Callaway, R. M.: Positive interactions in communities, Trends Ecol. Evol., 9, 191-193, 1994.

Braun-Blanquet, J. and Bolos, O.: Les groupements vegetaux du basin moyen de l'Ebre et leur dynamisme, Anales de la Estación Experimental de Aula Dei, 5, 1-266, 1957.

Breckle, S. W.: Halophytic and gypsophytic vegetation of the Ebro basin at los Monegros, Boletin de la Sociedad Entomologica Aragonesa, 24, 101-104, 1998.
Bruno, J. F., Stachowicz, J. J., and Bertness, M. D.: Inclusion of facilitation into ecological theory, Trends Ecol. Evol., 18, 119125, 2003.

Castro, J., Zamora, R., Hodar, J. A., Gomez, J. M., and GomezAparicio, L.: Benefits of using shrubs as nurse plants for reforestation in mediterranean mountains: a 4-year study, Restor. Ecol., 12, 352-358, 2004.

Cavieres, L. A., Badano, E. I., Sierra-Almeida, A., GomezGonzalez, S., and Molina-Montenegro, M. A.: Positive interactions between alpine plant species and the nurse cushion plant Laretia acaulis do not increase with elevation in the Andes of central Chile, New Phytol., 169, 59-69, 2006.

Cavieres, L. A., Brooker, R. W., Butterfield, B. J., Cook, B. J., Kikvidze, Z., Lortie, C. J., MIchalet, R., Pugnaire, F. I., Schob, C., Xiao, S., Anthelme, F., Bjork, R. G., Dickinson, K. J. M., Cranston, B. H., Gavilan, R., Gutierrez-Giron, A., Kanka, R., Maalouf, J. P., Mark, A. F., Noroozi, J., Parajuli, R., Phoenix, G. K., Reid, A. M., Ridenour, W. M., Rixen, C., Wipf, S., Zao, L., Escudero, A., Zaitchik, B. F., Lingua, E., Aschenboug, E. T., and Callaway, R. M.: Facilitative plant interactions and climate simultaneously drive alpine plant diversity, Ecol. Lett., 17, 193202, 2014.

de Bello, F., Leps, J., and Sebastia, M. T.: Grazing effects on the species-area relationship: variation along a climatic gradient in NE Spain, J. Veg. Sci., 18, 25-34, 2007.

Doreian, P. and Mrvar, A.: Partitioning signed social networks, Soc. Networks, 31, 1-11, 2009.

du Toit, G. N., Snyman, H. A., and Malan, P. J.: Physical impact of grazing by sheep on soil parameters in the nama karoo shrubland/grass rangeland of South Africa, J. Arid Environ., 73, 804810, 2009.

El Consejo De Las Comunidades Europeas: Directiva 92/43/CEE del Consejo, de 21 de mayo de 1992, relativa a la conservación de los hábitats naturales y de la fauna y flora silvestres. Diario Oficial de las Comunidades Europeas, 7-50, 1992.

Escudero, A.: Vegetación gypsicola mediterranea (Gypsophiletalia), Bases ecologicas preliminares para la conservación de los tipos de habitat de interes comunitario en España, Ministerio de Medio AMbiente, Medio Rural y Marino Madrid, 2009.

Escudero, A., Somolinos, R. C., Olano, J. M., and Rubio, A.: Factors controlling the establishment of Helianthemum squamatum, an endemic gypsophile of semiarid Spain, J. Ecol., 87, 290-302, 1999.

Fowler, N.: The role of competition in plant communities in arid and semiarid regions, Annu. Rev. Ecol. Syst., 17, 89-110, 1986.

Goodall, D. W.: Some considerations in the use of point quadrats for the analysis of vegetation, Aust. J. Sci., 5, 1-41, 1952.

Gotelli, N. J.: Null model analysis of species co-occurrence patterns, Ecology, 81, 2606-2621, 2000.

Graff, P., Aguiar, M. R., and Chaneton, E. J.: Shifts in positive and negative plant interactions along a grazing intensity gradient, Ecology, 88, 188-199, 2007.

Guimera, R. and Amaral, L. A. N.: Cartography of complex networks: modules and universal roles, J. Stat. Mech.-Theory E., 2005, P02001, doi:10.1088/1742-5468/2005/02/P02001, 2005.

Heleno, R., Garcia, C., Jordano, P., Traveset, A., Gomez, J. M., Bluthgen, N., Memmott, J., Moora, M., Cerdeira, J., RodriguezEcheverria, S., Freitas, H., and Olesen, J.: Ecological networks: 
delving into the architecture of biodiversity, Biol. Letters, 10, 20131000, doi:10.1098/rsbl.2013.1000, 2014.

Howard, T. G. and Goldberg, D. E.: Competitive response hierarchies for germination, growth, and survival and their influence on abundance, Ecology, 82, 979-990, 2001.

Ings, T. C., Montoya, J. M., Bascompte, J., Bluthgen, N., Brown, L., Dormann, C. F., Edwards, F., Figueroa, D., Jacob, U., Jones, J. I., Lauridsen, R. B., Ledger, M. E., Lewis, H. M., Olesen, J. M., Van Veen, F. J. F., Warren, P. H., and Woodward, G.: Ecological networks - Beyond food webs, J. Anim. Ecol., 78, 253-269, 2009.

James, F. C. and McCulloch, C. E.: Multivariate analysis in ecology and systematics: panacea or pandora's box?, Annual Review in Ecology and Systematics, 21, 129-166, 1990.

Maestre, F. T., Valladares, F., and Reynolds, J. F.: The stressgradient hypothesis does not fill all relationships between plantplant interactions and abiotic stress: further insights from arid environments, J. Ecol., 94, 17-22, 2006.

Maestre, F. T., Callaway, R. M., Valladares, F., and Lortie, C. L.: Refining the Stress Gradient Hypothesis for competition and facilitation in plant communities, J. Ecol., 97, 199-205, 2009.

Martinez-Hernandez, F., Perez-Garcia, F. J., Garrido-Becerra, J. A., Mendoza-Fernandez, A. J., Medina-Cazorla, J. M., MartinezNieto, M. I., Merlo, M. E., and Mota, J. F.: The distribution of iberian gypsophilous flora as a criterion for conservation policy, Biodivers. Conserv., 20, 1353-1364, 2011.

McNaughton, S. J.: On plants and herbivores, Am. Nat., 128, 765770, 1986.

Meyer, S. E.: The ecology of gypsophile endemism in the eastern Mojave desert, Ecology, 67, 1303-1313, 1986.

Michalet, R., Brooker, R. W., Cavieres, L. A., Kikvidze, Z., Lortie, C. J., Pugnaire, F. I., Valiente-Banuet, A., and Callaway, R. M.: Do biotic interactions shape both sides of the humped-back model of species richness in plant communities?, Ecol. Lett., 9, 767-773, 2006.

Milchunas, D. G. and Lauenroth, W. K.: Quantitative effects of grazing on vegetation and soils over a global range of environments, Ecol. Monogr., 63, 327-366, 1993.

Mota, J. F., Sanchez-Gamez, P., and Guirado, J. S.: Diversidad vegetal de las yeseras Ibericas: el reto de los archipielagos edaficos para la biologia de la conservacion, ADI-Mediterraneo Asesores Consultores, Almeria, 2011.

Newman, M. E. J.: The structure and function of complex networks, J. Soc. Ind. Appl. Math., 45, 167-256, 2003.

Olff, H. and Ritchie, M. E.: Effects of herbivores on grassland plant diversity, Trends Ecol. Evol. 13, 261-265, 1998.

Palacio, S., Escudero, A., Montserrat-Marti, G., Maestro, M., Milla, R., and Albert, M. J.: Plants living on gypsum: beyond the specialist model, Ann. Bot.-London, 99, 333-343, 2007.

Parsons, R. F.: Gypsophily in plants - a review, Am. Midl. Nat., 96, 1-20, 1976.

Pueyo, Y., Alados, C. L., Maestro, M., and Komac, B.: Gypsophile vegetation patterns under a range of soil properties induced by topographical position, Plant Ecol., 189, 301-311, 2007.

Pueyo, Y., Alados, C. L., Barrantes, O., Komac, B., and Rietkerk, M.: Differences in gypsum plant communities associated with habitat fragmentation and livestock grazing, Ecol. Appl., 18, 954-964, 2008.
Pueyo, Y., Alados, C. L., Garcia-Avila, B., Kefi, S., Maestro, M., and Rietkerk, M.: Comparing direct abiotic amelioration and facilitation as tools for restoration of semiarid grasslands, Restor. Ecol., 17, 908-916, 2009.

Pueyo, Y., Moret-Fernandez, D., Saiz, H., Bueno, C. G., and Alados, C. L.: Relationships Between Plant Spatial Patterns, Water Infiltration Capacity, and Plant Community Composition in Semiarid Mediterranean Ecosystems Along Stress Gradients, Ecosystems, 16, 452-466, 2013.

Pugnaire, F., Armas, C., and Valladares, F.: Soil as a mediator in plant-plant interactions in a semi-arid community, J. Veg. Sci., 15, 85-92, 2004.

Pugnaire, F. I. and Luque, M. T.: Changes in plant interactions along a gradient of environmental stress, Oikos, 93, 42-49, 2001.

Pugnaire, F. I., Haase, P., and Puigdefabregas, J.: Facilitation between higher plant species in a semiarid environment, Ecology, 77, 1420-1426, 1996.

Robles, A. B. and Passera, C.: Native forage shrub species in southeastern Spain: forage species, forage phytomass, nutritive value and carrying capacity, J. Arid Environ., 30, 191-196, 1995.

Romao, R. L. and Mota, J. F.: Gypsum physical soil crusts and the existence of gypsophytes in semi-arid central Spain, Plant Ecol., 181, 127-137, 2005.

Rook, A. J., Dumont, B., Isselstein, J., Osoro, K., Wallis de Vries, M. F., Parente, G., and Mills, J.: Matching type of livestock to desired biodiversity outcomes in pastures - a review, Biol. Conserv., 119, 137-150, 2004.

Saiz, H. and Alados, C. L.: Changes in semi-arid plant species associations along a livestock grazing gradient, PLOS One, 7, e40551, doi:10.1371/journal.pone.0040551, 2012

Sala, O. E. and Aguiar, M. R.: Origin, maintenance, and ecosystem effect of vegetation patches in arid lands, Fifth International Rangeland Congress, 1995.

Smit, C., Rietkerk, M., and Wassen, M. J.: Inclusion of biotic stress (consumer pressure) alters predictions from the stress gradient hypothesis, J. Ecol., 97, 1215-1219, 2009.

Soliveres, S., Eldridge, D. J., Hemmings, F., and Maestre, F. T.: Nurse plant effects on plant species richness in drylands: the role of grazing, rainfall and species specificity, Perspect. Plant Ecol., 14, 402-410, 2012.

Tewksbury, J. J. and Lloyd, J. D.: Positive interactions under nurseplants: spatial scale, stress gradients and benefactor size, Oecologia, 127, 425-434, 2001.

Tirado, R. and Pugnaire, F.: Community structure and positive interactions in constraining environments, Oikos, 111, 437-444, 2005.

Traag, V. A. and Bruggeman, J.: Community detection in networks with positive and negative links, Phys. Rev. E, 80, 036115, doi:10.1103/PhysRevE.80.036115, 2009.

Valiente-Banuet, A. and Verdu, M.: Facilitation can increase the phylogenetic diversity of plant communities, Ecol. Lett., 10, 1029-1036, 2007.

Van de Maarel, E. and Franklin, J.: Vegetation ecology, Wiley, Chichester, 2005.

Verdu, M. and Valiente-Banuet, A.: The nested assembly of plant facilitation networks prevents species extinctions, Am. Nat., 172, 751-760, 2008. 
Verdu, M. and Valiente-Banuet, A.: The relative contribution of abundance and phylogeny to the structure of plant facilitation networks, Oikos, 120, 1351-1356, 2011.
Ward, J. H.: Hierarchical grouping to optimize and objective function, J. Am. Stat. Assoc., 58, 236-244, 1963. 